\title{
An Excellent SCCHP Design Project in Thermal-fluids Education
}

\author{
Yongjian Gu, Ph.D., P.E. \\ The United State Merchant Marine Academy, 300 Steamboat Rd, Kings Point, New York, 11024. USA
}

\begin{abstract}
Thermodynamics, fluid mechanics, and heat transfer are three core courses playing key roles in thermal-fluids education. For students majoring in thermal-fluids, a senior design project is usually assigned to train them knowing how and where these course knowledge is applied in engineering. The project should be proper and practical, not only to boost design interests of the students, but also to help their future career development. In the paper, the author describes a design project, solar-assisted combined cooling, heating, and power (SCCHP) plant, which is designed per author's many year experience of professional work in consulting companies and teaching in colleges. The SCCHP plant is composed of a solar heating system including solar energy collectors and a high efficiency heat exchanger, a steam power system including a steam turbine, cooling tower, and condenser, and the cooling and heating of the HVAC system including an absorption/compression chiller, a cooling tower, and an air handling unit (AHU). The students apply the knowledge of thermodynamics, fluid mechanics, and heat transfer to understand the plant working principle and perform the heat balance calculation. In the paper, the author illustrates the design procedure and presents sketches of the SCCHP plant and the subsystems of solar heating, steam power, and cooling and heating of HVAC. The equations of thermodynamics, fluid mechanics, and heat transfer for calculation and analysis are described, respectively. The design project of the SCCHP plant has been used partially or completely for a few years. It has been highly appreciated by the students, even after their graduation when they were working in companies.
\end{abstract}

Keywords: Senior Design Project, Thermodynamics, Fluid Mechanics, Heat Transfer, SolarAssisted Combined Cooling, Heating, and Power (SCCHP), Heating, Ventilation, and Air Conditioning (HVAC)

\section{INTRODUCTION}

Solar heat is a renewable, sustainable, and green energy resource. A solar-assisted combined cooling, heating, and power (SCCHP) plant is an integral system to uses solar heat as the only energy input to provide electricity, process heating, cooling and heating in the heating, ventilation, and air condition (HVAC) system. For the students majoring in thermal-fluids, the SCCHP plant is an excellent senior design project which is proper and practical. In the heat balance calculation of an SCCHP plant, the students have opportunity to apply the knowledge of thermodynamics, fluid mechanics, and heat transfer which are the three core courses in 
thermal-fluids they learned in the college/university. The design project of SCCHP will train the students knowing how and where these course knowledge is applied in engineering. The project will not only enable to boost design interests of the students, but also to help their future career development. The purpose of the design project of an SCCHP is to let students

1) Know renewable, sustainable, and green energy. Solar heat is one of the energy resources.

2) Understand an SCCHP plant is an integral system. For heat balance calculation, the course knowledge of thermodynamics, fluid mechanics, and heat transfer need to be employed.

3) Know engineering design requirement and drawings.

4) Get familiar how to perform the heat balance in the thermal-fluids system and equations applied in the heat balance calculation.

In the followings of the paper, the sketches of the SCCHP plant and the subsystems of solar heating, steam power plant, process heating, and cooling and heating of HVAC system are presented. The major equations related of thermodynamics, fluid mechanics, and heat transfer in heat balance calculation of each subsystem are illustrated, respectively. Students should know the steps and equations to perform the heat balance in each system and are familiar the meaning of parameters presented in the equation.

\section{SOLAR-ASSISTED COMBINED COOLING, HEATING, AND POWER PLANT (SCCHP)}

A solar-assisted combined cooling, heating, and power (SCCHP) plant is a solar thermal plant, also known as "concentrated solar a thermal plant". The plant is different from the photovoltaic (PV) power plant in which flat panels are used and the solar heat from incident sunlight is directly converted into electricity in the panels. In the SCCHP plant, concentrated solar heat collector is applied. The solar heat is used to generate steam and the steam is expanded in a steam turbine to produce the power. Process heating can be provided in the steam power system which is called cogeneration. Cooling and heating of the HVAC system is able to be provided

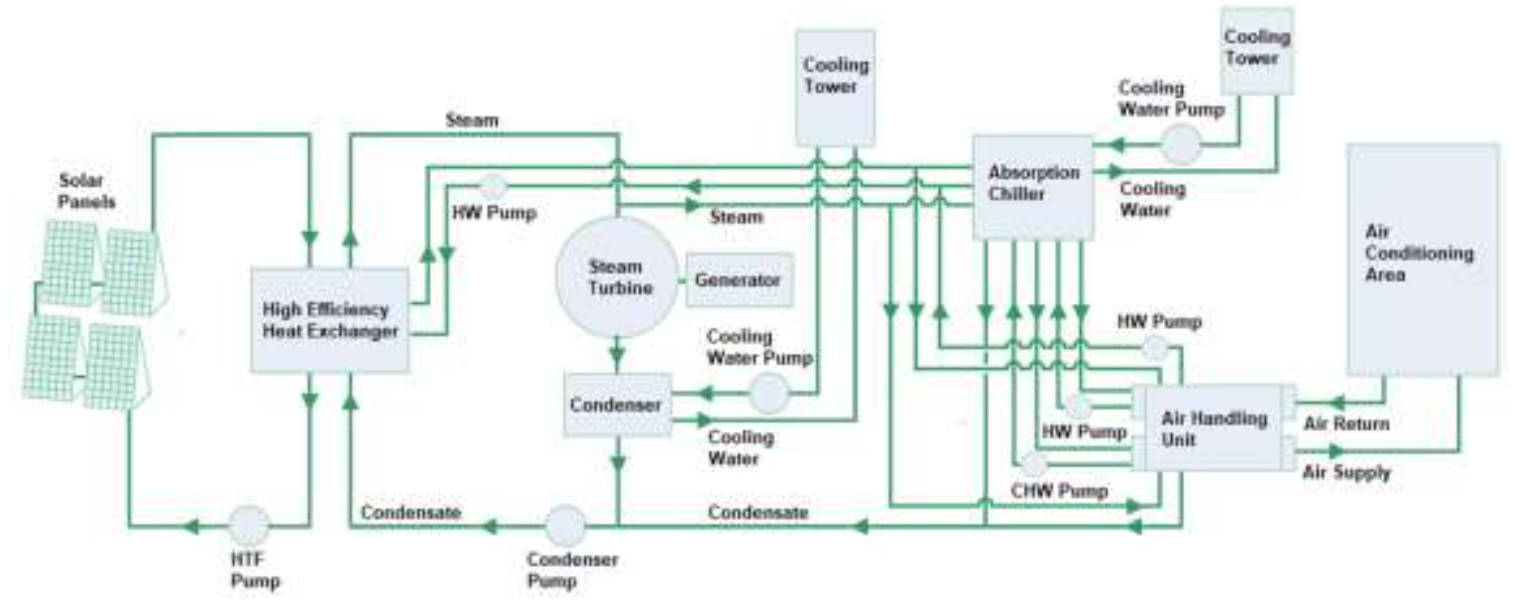

Fig. 1. System Diagram of a Typical SCCHP Plant

from an absorption chiller. The system diagram of a typical SCCHP plant is shown in Fig.1. The SCCHP plant basically is composed of three major subsystems. They are solar system, steam power system, and cooling and heating of HVAC system. The solar heating system 
majorly includes solar heat collectors, a cooling tower, and a high efficiency heat exchanger. The steam power system majorly includes a steam turbine and a condenser. The cooling and heating of (HVAC) system majorly includes an absorption chiller, a cooling tower, and an air handling unit (AHU). Each system needs pumps to circulate fluids. The working principle/mechanism of the SCCHP is not difficult to be understood by the students majoring in thermal-fluids since they have completed thermodynamics, fluid mechanics, and heat transfer which are three core courses applied in power plant design. The subsystems in the SCCHP plant are categorized in Fig. 2.

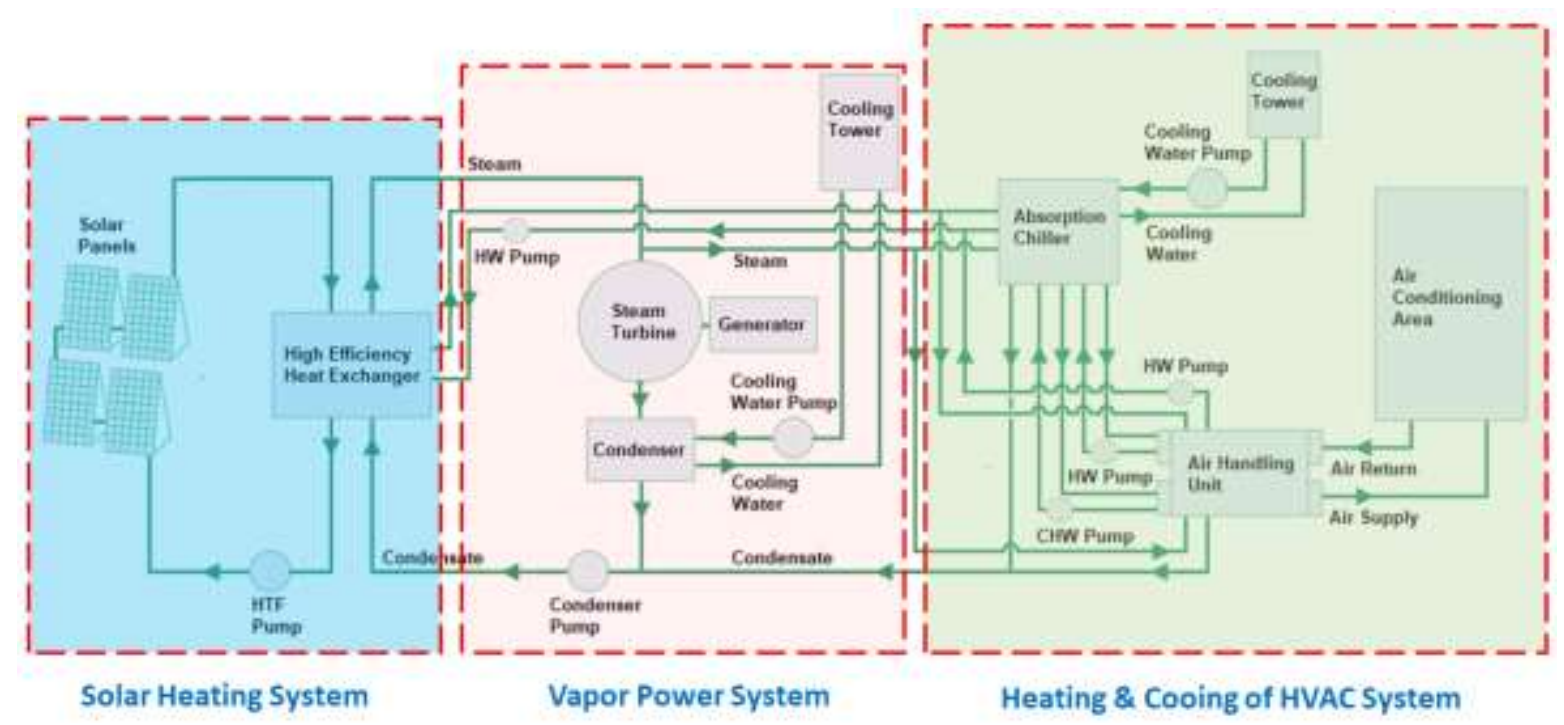

Fig. 2. Subsystems of an SCCHP Plant

The energy cascade in an SCCHP Plant can be expressed in a Sankey diagram. It can be seen the only energy input in the SCCHP plant is solar heat. The diagram gives a clear view of energy distribution in the SCCHP plant.

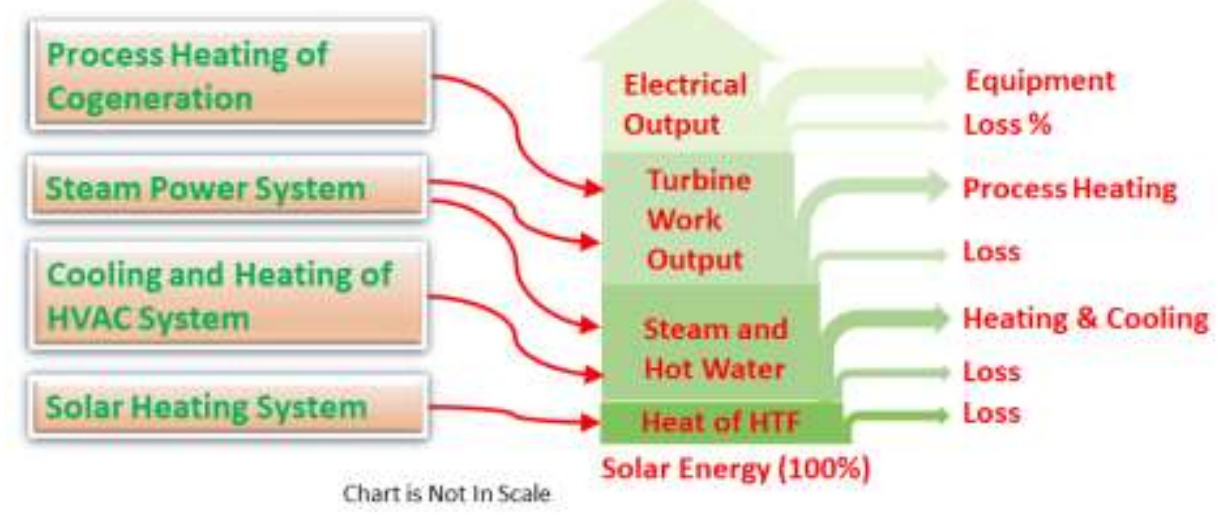

Fig. 3.Energy Cascade in an SCCHP Plant

\section{SOLAR HEATING SYSTEM}

In a solar thermal power plant, different types of concentrated solar heat collector can be used, such as parabolic trough concentrator or heliostat central receiver. The project considers to use the parabolic trough concentrator. In addition, there are two kinds of the solar heating systems. One is the steam required in the steam power system is generated directly in the parabolic 
trough concentrator, which is called direct steam generation (DSG). Another is indirect steam generation in which the fluid called heat transfer fluid (HTF) is employed as a working fluid and the steam is generated in a high efficiency HTF-water heat exchange. In the project, the solar heating system is indirect steam generation and parabolic trough concentrator. The solar heating system and parabolic trough solar heat receiver is shown in Fig. 4. In the figure, the heat balance and required course knowledge are illustrated for student understanding.

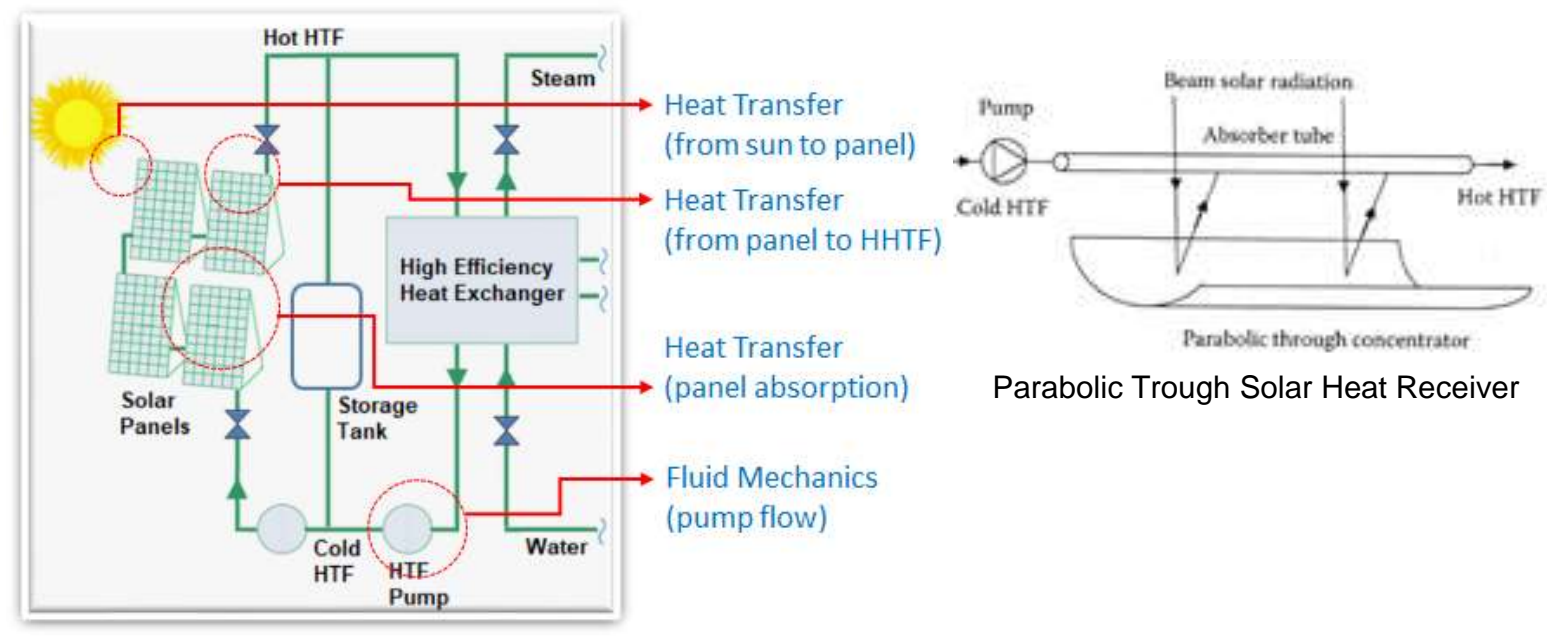

Fig. 4. Solar Heating System and Parabolic Trough Solar Heat Receiver

Solar radiation received by the concentrator and the receiver heat loss per unit time are $E_{\mathrm{P}}$ and $O_{\text {loss }}$, respectively

$$
\begin{aligned}
& E_{\mathrm{P}}=A_{\mathrm{ap}} I_{\mathrm{bc}} \eta_{\mathrm{opt}} \quad \mathrm{W} \\
& \left.\left.Q_{\text {loss }}=A_{\mathrm{ap}} U_{\mathrm{c}, \mathrm{e}} / C\right)\left(T_{\mathrm{in}}-T_{\mathrm{a}}\right)\right] \quad \mathrm{W}
\end{aligned}
$$

Where $A_{\text {ap }}$ - the aperture area of the concentrator $\left(\mathrm{m}^{2}\right)$

$I_{\mathrm{bc}}$ - the beam solar radiation flux incident on the concentrator aperture $\left(\mathrm{W} / \mathrm{m}^{2}\right)$

$\eta_{\mathrm{opt}}-$ the effective optical efficiency of the solar concentrating collector

$U_{\mathrm{c}, \mathrm{e}}-$ the effective overall heat loss coefficient of receiver $\left(\mathrm{W} / \mathrm{m}^{2} \mathrm{~K}\right)$

$C$ - the concentration ratio of the solar concentrating collector

$T_{\text {in }}$ - the temperature of the HTF at the receiver inlet $(\mathrm{K})$

$T_{\mathrm{a}}$ - the ambient air temperature $(\mathrm{K})$

Obviously, the solar heat gained by the absorber defined as the useful heat gain pre unit time $Q_{\mathrm{c}}$ is:

$$
Q_{\mathrm{c}}=A_{\mathrm{ap}}\left[I_{\mathrm{bc}} \eta_{\mathrm{opt}}-\left(U_{\mathrm{c}, \mathrm{e}} / C\right)\left(T_{\mathrm{in}}-T_{\mathrm{a}}\right)\right] \quad \mathrm{W}
$$

The solar heat gain will increase the temperature of the HTF circulating in the solar heating system. Therefore, the HTF enthalpy $h_{\text {out }}$ and temperature $T_{\text {out }}$ at the absorber outlet are, respectively

$$
\begin{aligned}
& \left.h_{\text {out }}=h_{\text {in }}+\mathrm{Q}_{\mathrm{d}} / m_{\mathrm{HTF}}\right) \quad \mathrm{J} / \mathrm{kg} \\
& T_{\text {out }}=T_{\text {in }}+\mathrm{Q}_{\mathrm{d}}\left(m_{\mathrm{HTF}} \times c_{\mathrm{p}}\right) \quad \mathrm{K}
\end{aligned}
$$


Where $h_{\text {in }}-$ the HTF enthalpy at the absorber inlet (K)

$m_{\mathrm{HTF}}-$ the HTF mass flow rate $(\mathrm{kg} / \mathrm{s})$

$c_{\mathrm{p}}-$ the specific heat of $\operatorname{HTF}(\mathrm{J} / \mathrm{kgK})$

The pump head $h$ p required for HTF circulation in the solar heating system can be determined:

$$
h_{\mathrm{p}}=\Delta z+\Delta p / \rho g+\Delta \mathrm{v}^{2} / 2 \mathrm{~g}+\mathrm{v} 2\left(\mathrm{fL} / \mathrm{d}+\sum \mathrm{K}\right) / 2 \mathrm{~g}
$$

Where $\Delta z$ - the elevation difference of HTF inlet and outlet on the HTF heat exchanger $(\mathrm{m})$

$\Delta p$ - the pressure difference across the HTF heat exchanger $(\mathrm{kPa})$

$\Delta \mathrm{v}$ - the velocity difference of HTF inlet and outlet on the HTF heat exchanger $(\mathrm{m} / \mathrm{s})$

$\rho$ - the density of HTF $\left(\mathrm{kg} / \mathrm{v}^{3}\right)$

$g$ - the gravitational velocity $\left(\mathrm{m}^{2} / \mathrm{s}\right)$

$\mathrm{v}$ - the velocity of HTF in the pipe of the solar heating system $(\mathrm{m} / \mathrm{s})$

$f$ - the friction factor of flow in the pipe

$L$ - the length of the HTF piping (m)

$d$ - the diameter of the pipe $(\mathrm{m})$

$K-$ the minor loss coefficient from valves, elbows, etc.

Then, the pump power can be obtained

$$
P_{\mathrm{p}}=\rho g Q h_{\mathrm{p}} \quad \mathrm{W}
$$

Where $Q-$ HTF volume flow rate $\left(\mathrm{m}^{3} / \mathrm{s}\right)$

The HTF flow is circulating in the solar heating system and transferring the heat obtained from the solar receiver to the water circulating in the steam power system and produce the steam required in the steam turbine.

\section{STEAM POWER SYSTEM}

The steam to the steam turbine in the steam power system is generated in the high efficiency heat exchanger. The steam expands in the steam turbine to produce shaft work and the steam condensate goes back to the high efficient heat exchanger to complete a cycle. The steam turbine is operating on Rankine cycle. Fig. 5 shows the steam power system and property diagram of the Rankine cycle. In the figure, the heat balance and required course knowledge are illustrated for student understanding.
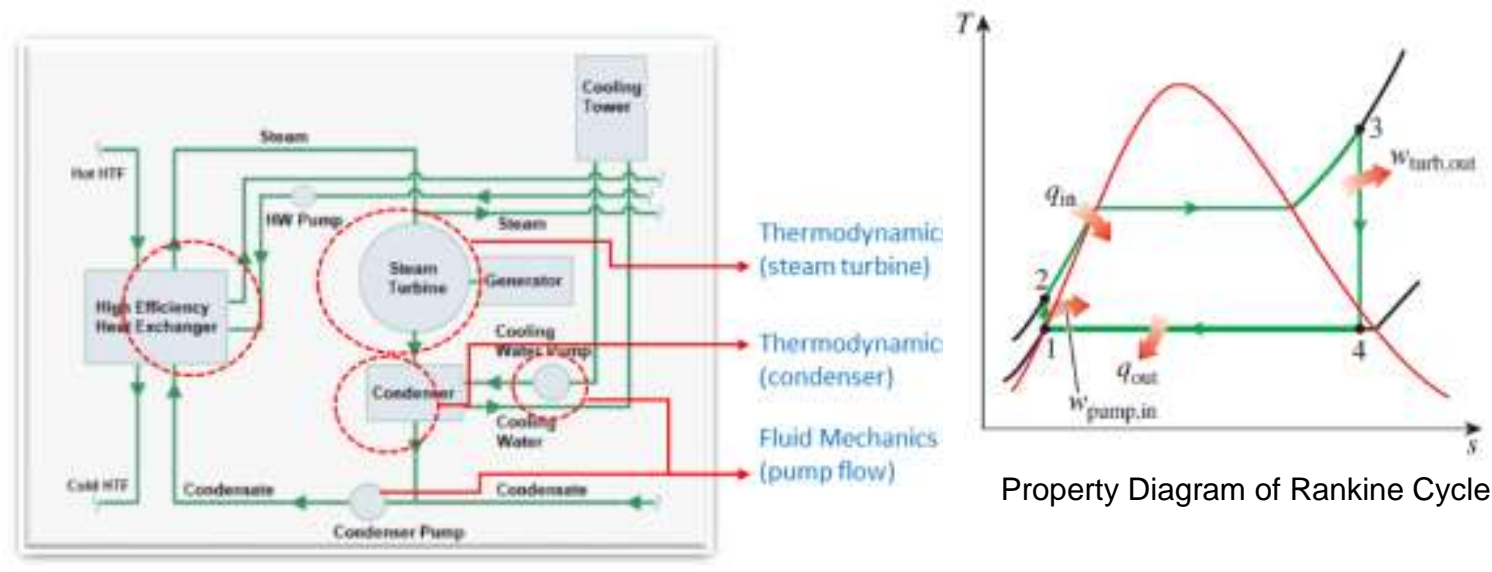

Fig. 5. Steam Power System 
Steam flow rate generated in the steam power system $m_{\mathrm{s}}$ will be determined by:

$$
m_{\mathrm{s}}=\eta_{\mathrm{HEX}} Q_{\mathrm{c}} /\left(h_{\mathrm{s}}-h_{\mathrm{w}}\right) \quad \mathrm{kg} / \mathrm{s}
$$

Where $\eta_{\mathrm{HEX}}-$ the efficiency of the high efficiency HTF heat exchanger

$h_{\mathrm{s}}$ - the enthalpy of the superheated steam out of HTF heat exchanger $(\mathrm{kJ} / \mathrm{kg})$

$h_{\mathrm{w}}-$ the enthalpy of the condensate back from condenser. $(\mathrm{kJ} / \mathrm{kg})$

Hence, the shaft work $W_{\mathrm{t}}$ from the steam turbine is given as:

$$
W_{\mathrm{t}}=m_{\mathrm{s}}\left(h_{\mathrm{in}}-h_{\text {out }} \quad \mathrm{W}\right.
$$

Where $m_{\mathrm{s}}$ - the mass flow rate of steam to the steam turbine $(\mathrm{kg} / \mathrm{s})$

$h_{\text {in }}$ - the enthalpy of the superheated steam entering in the steam turbine $(\mathrm{kJ} / \mathrm{kg})$

$h_{\text {out }}-$ the enthalpy of the superheated steam exiting of the steam turbine $(\mathrm{kJ} / \mathrm{kg})$

$h_{\text {in }}$ and $h_{\text {out }}$ can be determined by from steam tables per the steam pressure and temperature. Finally, the electric power output $P_{\text {ele }}$ of the power system is

$$
P_{\text {ele }}=W_{\mathrm{t}} \eta_{\mathrm{g}} \quad \mathrm{W}
$$

Where $\eta_{\mathrm{g}}$ - efficiency of the electric generator

The cooling water flow to the cooling tower and the condensate flow through the condenser can be decided by the heat balance equation of heat transfer. The required pump head and motor power will be estimated by using the same equations (3-7) and (3-8).

\section{PROCESS HEATING OF COGENERATION}

The steam power system shown in Fig. 5 can be modified to a cogeneration to provide process heating. The process heating is employed for industrial and commercial application out of the SCCHP plant. Such a process heating can be obtained from two methods. One is from the cooling water received steam latent heat in the condenser. Another uses a closed type HEX. The former method, however, the power output of the steam turbine will be very possibly affected by the process heating load. In the project, therefore, the closed type HEX for processing heating of is applied. Such a cogeneration system is shown in Fig. 6. In the figure, the heat balance and required course knowledge are illustrated for student understanding.
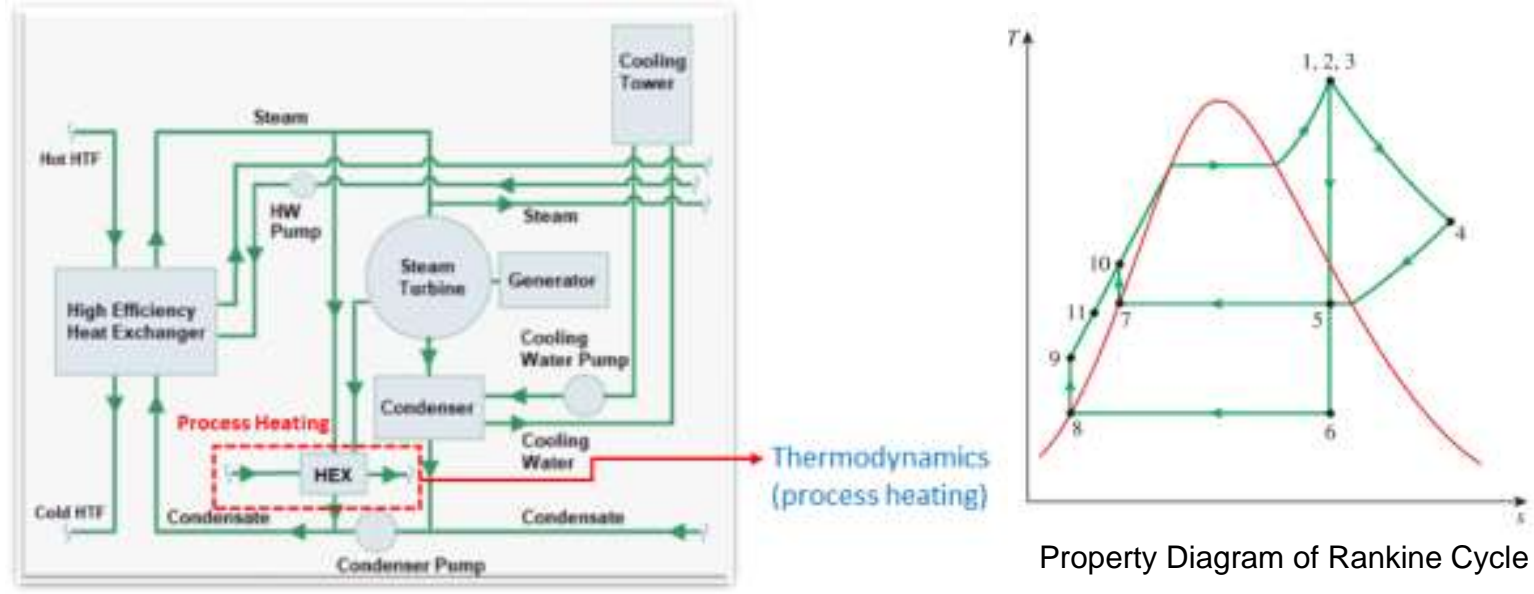

Fig. 6. Process Heating of Cogeneration 
The process heating of cogeneration $Q_{\mathrm{h}}$ is decided by

$$
Q_{\mathrm{h}}=m_{\mathrm{s}}\left(h_{\mathrm{s}}-h_{\mathrm{c})} \quad \mathrm{W}\right.
$$

Where $m_{\mathrm{s}}$ - the mass flow rate of steam to the closed HEX $(\mathrm{kg} / \mathrm{s})$

The outlet temperature of the process heating flow to the industrial and commercial application will be

$$
T_{\text {out }}=T_{\text {in }}+Q_{\mathrm{h}} /\left(m_{\mathrm{h}} c_{\mathrm{p})} \quad \mathrm{K}\right.
$$

Where $m_{\mathrm{h}}$ - the mass flow rate of process heating $(\mathrm{kg} / \mathrm{s})$

$T_{\text {in }}$ - the inlet temperature of the process heating flow $(\mathrm{K})$

$c_{\mathrm{p}}$ - the specific heat at constant pressure of the process heating flow $(\mathrm{kJ} / \mathrm{kgK})$

\section{COOLING AND HEATING OF HVAC SYSTEM}

The cooling and heating of HVAC system is shown in Fig.7. The chilled water out of the chiller is supplied to the air handling unit (AHU) to cool the air which will circulate in the HVAC system. In such a system, the chiller is a key equipment in the cooling operation. There are two types of chillers, the electric chiller and the absorption chiller. In the project, the absorption chiller is recommended. Not only the absorption chiller will consume less electricity, but also the absorption chiller is also able to provide heating. The heating, however, can be provided either the hot water or steam from the high efficiency heat exchanger in the steam power or from the absorption chiller. In the figure, the heat balance and required course knowledge are clearly illustrated.

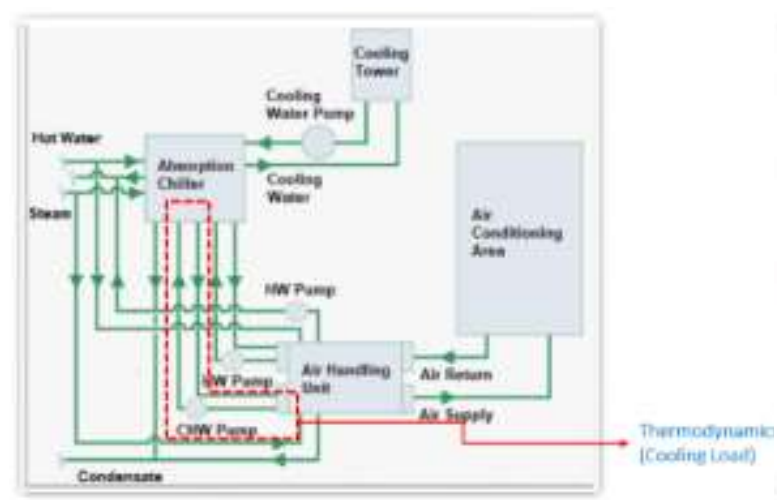

Cooling

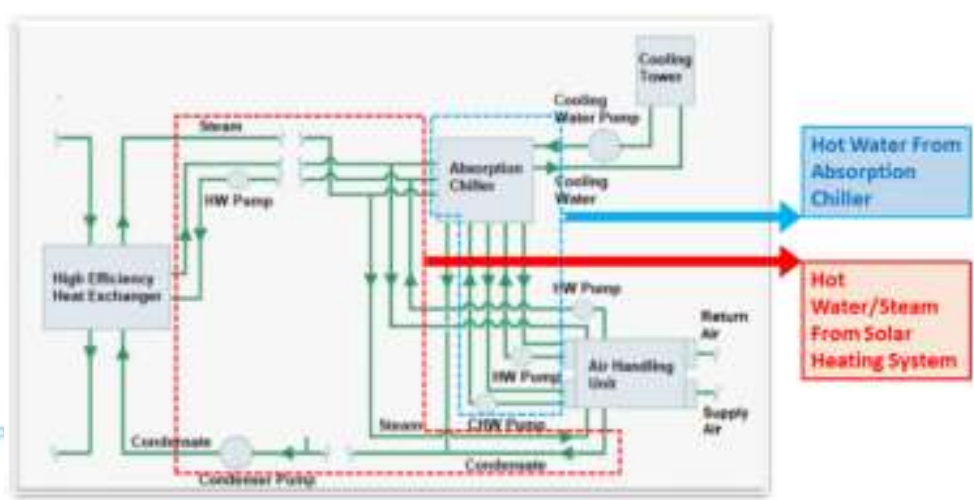

Heating

Fig. 7. Cooling and Heating of HVAC System

Many students may not be familiar with the absorption chiller. So it is necessary to give a brief description of the absorption chiller.

1) Absorption Chiller Working Mechanism

An absorption chiller is also known as a "thermally driven non-electric chiller". Comparing with the electric chiller, the energy input of the absorption chiller is heat (steam, hot water, or others) instead of electricity. In an absorption chiller, the thermal "compressor" functioning as a refrigerant generator replaces the electric compressor in the electric chiller. The refrigerant 
of cooling in HVAC system is water. Fig. 8 gives the absorption chiller concept and working mechanism.

A liquid mixture of lithium-bromide and water is heated in a drum. The lithium-bromide is working as a refrigerant (water) carrier. The processes included in the absorption chiller are:

- Water vapor rises in the generator and passes through a condenser in which the water vapor becomes condensate.

- The water (condensate) goes through the expansion valve as the refrigerant sprayed on the evaporator.

- The refrigerant (water) becomes vapor in evaporator chamber and absorbed by lithiumbromide in absorb chamber to form lithium-bromide/water mixture in liquid.

- The liquid mixture of lithium-bromide/water goes back to the generator to repeat the processes.

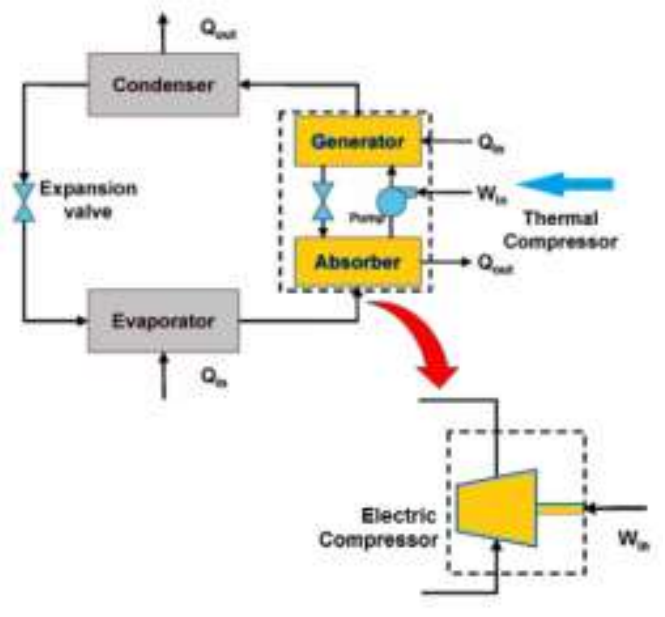

Absorption Chiller Concept

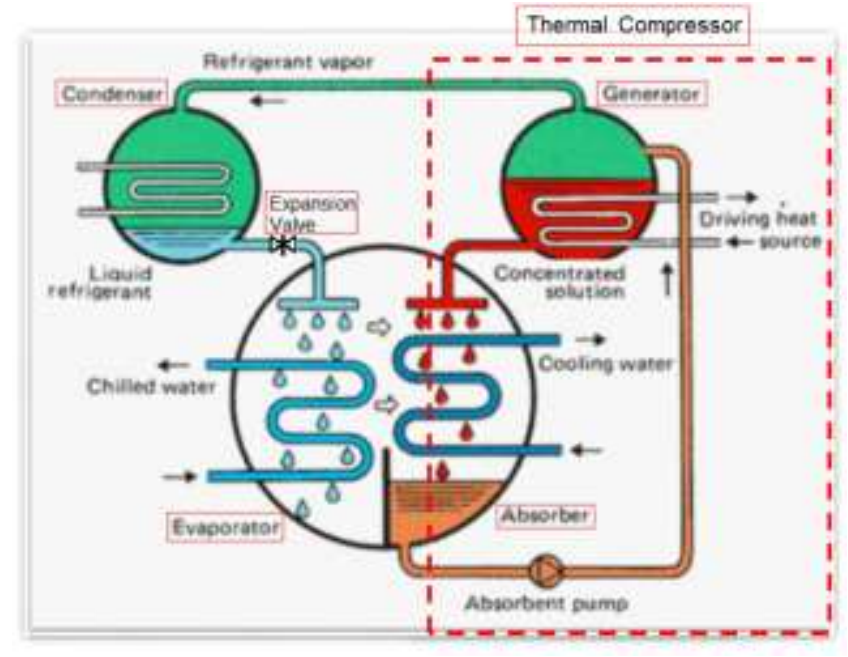

Working Mechanism

Fig. 8. The Absorption Chiller

2) Cooling and Heating from an Absorption Chiller

Except cooling function, the absorption chiller is also able to provide cooling heating. In the generator, the water vapor heats the water circulating in the hot water pipe. The hot water is used in the heating coiler located in the air handling unit (AHU) for heating purpose. Fig. 9 shows the configuration of the cooling and heating from an absorption chiller.

Using the psychometric chart as shown in Fig. 10, the cooling and heating load of HVAC system either from the absorption chiller or heating from high efficiency heat exchanger can be decided by the following equations:

$$
H_{\mathrm{c}}=4.5 \times C F M \times \Delta h \quad \mathrm{Btu} / \mathrm{hr}
$$

Where $H_{\mathrm{c}}-$ the cooling load of HVAC system (Btu/hr)

$C F M$ - the air flow rate in AHU (cft/min)

$\Delta h$ - the enthalpy difference of inlet air and outlet air in AHU (Btu/lbm.R)

$$
H_{\mathrm{h}}=1.08 \times C F M \times \Delta T \quad \mathrm{Btu} / \mathrm{hr}
$$


Where $H_{\mathrm{h}}$ - the heating load of HVAC system (Btu/hr)

$\Delta T$ - the temperature difference of inlet air and outlet air in AHU (R)

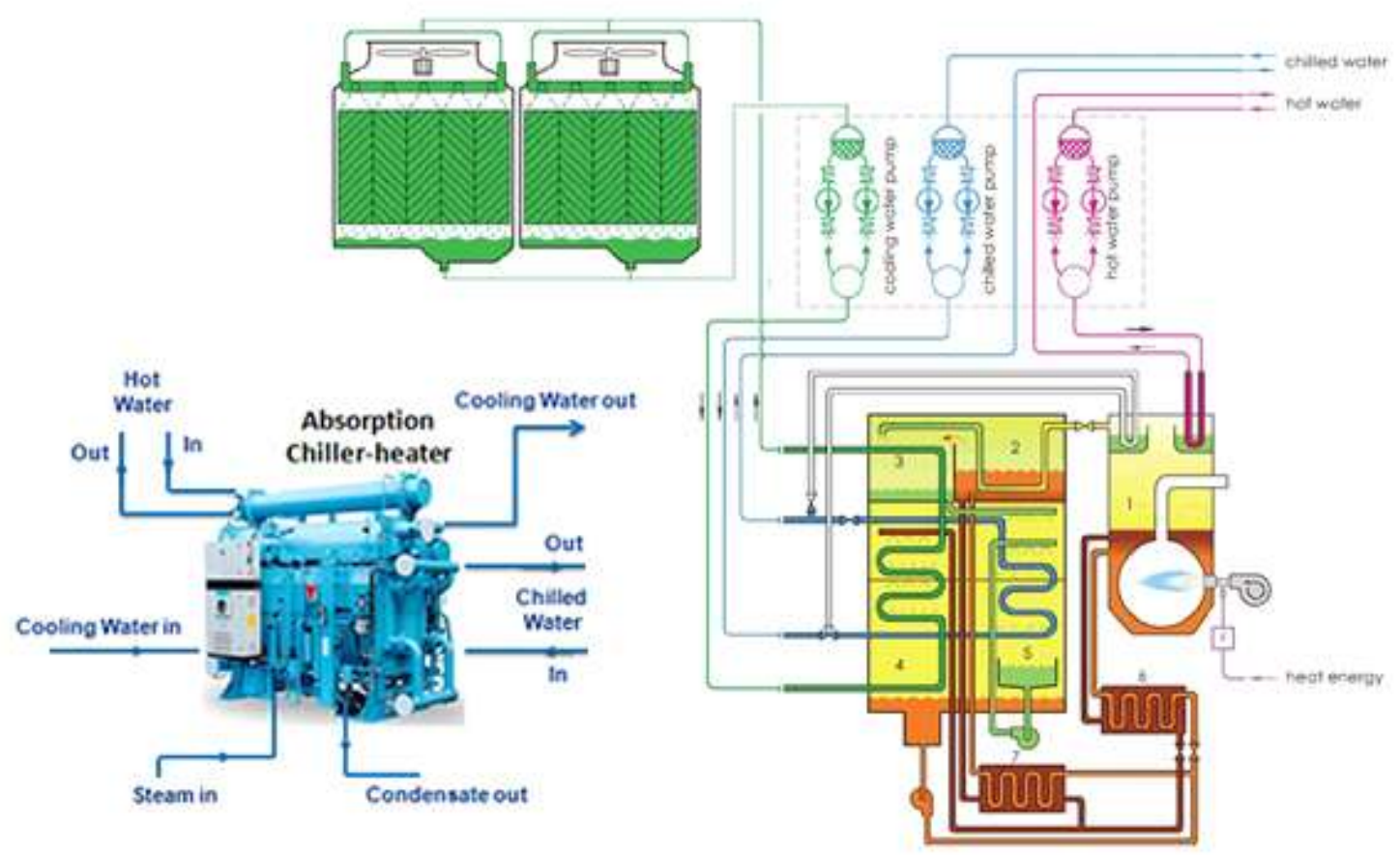

Fig. 9. Cooling and Heating from an Absorption Chiller

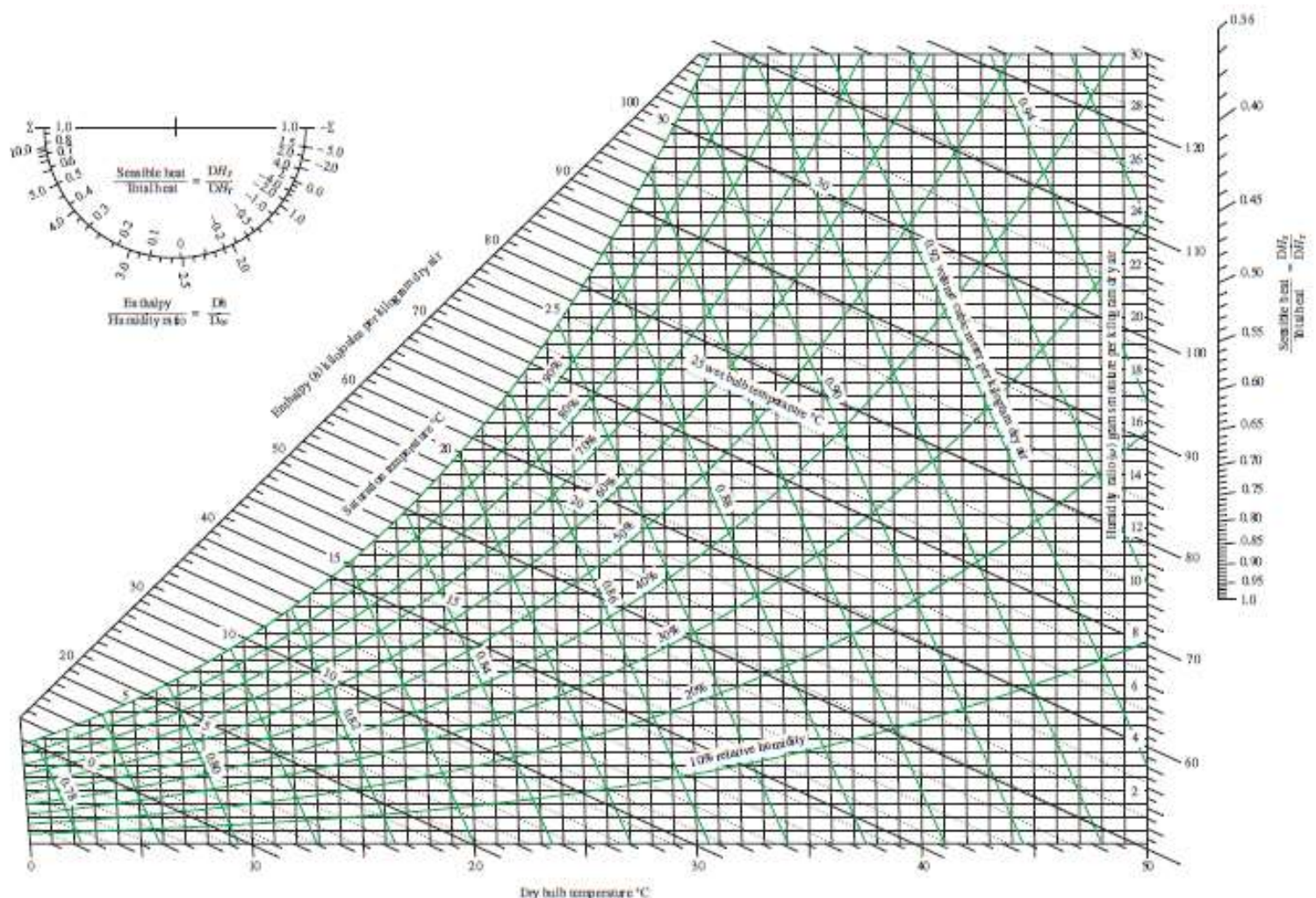

Fig. 10. Psychometric Chart 


\section{SUMMARY}

Thermodynamics, fluid mechanics, and heat transfer are three core courses playing key roles in thermal-fluids education. For students majoring in thermal-fluids, a senior design project is usually assigned to train them knowing how and where these course knowledge is applied in engineering. Per the author's many year experience of professional work in consulting companies and teaching in colleges/universities, the author believes the solar-assisted combined cooling, heating, and power (SCCHP) plant is an excellent project for them. The project not only can boost design interests of the students, but also help for their future career development. Through the heat balance calculation described in the paper, the students are able to know how and where these course knowledge is applied in engineering. Since the paper room limitation, some equipment and heat balance equations are not presented, such as the cooling tower and AHU. These equipment are covered in the design during the students are working on the project. The design project of the SCCHP plant has been used partially or completely for a few years. It has been highly appreciated by the students, even after their graduation when they were working in companies.

\section{REFERENCES}

1. Yunus A. Cengel, Michael A. Boles: Thermodynamics - An Engineering Approach. McGraw-Hill Edition. $8^{\text {th }}$ edition. 2015.

2. Frank M. White: Fluid Mechanics. McGraw-Hill Edition. 7th edition. 2011.

3. Yunus A. Cengel, Michael A. Boles: Fluid Mechanics - Fundamentals \& Applications. McGraw-Hill Edition. $3^{\text {rd }}$ edition. 2014.

4. Yunus A. Cengel, Michael A. Boles: Heat and Mass Transfer - Fundamentals \& Applications. McGraw-Hill Edition. 5 ${ }^{\text {th }}$ edition. 2015.

5. Yongjian Gu: Solar-Assisted Combined Cooling, Heating, and Power (SCCHP) Plant. Annual Seminar of Engineers of Joint Committee of Long Island (EJCLI). Long Island, NY. Februaryt 13, 2020 